\title{
UNIVERSUM
}

\section{DISOLUCIÓN, HIBRIDISMO, ATOMIZACIÓN Y FANTASMAGORÍA EN EL ARTE MODERNO Y CONTEMPORÁNEO}

\section{Dissolution, hybridism, atomization and phantasmagoria, in modern and contemporary art}

\section{Guillermo Aguirre Martínezi (iD}

${ }^{1}$ Universidad Complutense de Madrid, España.

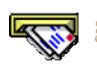

guillemo.a.m@ucm.es

\section{RESUMEN}

Con este texto se presenta un panorama en torno a la disolución formal del objeto escultórico a finales del XIX, y su deriva en la actualidad hacia una imagen atomizada e incluso evanescente. Para ello nos apoyaremos en los planteamientos de autores como Bauman, Lipovetsky o Maffesoli, entre otros. Asimismo, veremos cómo el creador actual expone un universo simbólico en el que el hibridismo se impone, al tiempo que la realidad virtual suplanta a la convencional.

PALABRAS CLAVE: escultura del siglo XX; arte contemporáneo; sociedad líquida; artes visuales; arte holográfico.

\section{ABSTRACT}

This paper shows the development of the sculpture throughout the rgth and zoth centuries in relation with the duality form/dissolution. Since this last duality, we will discuss about the contemporary art -whose image is above anything else atomized, as well as ghostly, evanescent-. We will explore the meaning of this change with the help of authors as Bauman, Lipovetsky or Maffesoli, among others. Finally, we will see how the contemporary artist exposes his imaginary by means of hybrid figures, as well as prioritizes the virtual reality above the common, ordinary one. KEYWORDS: sculpture of the twentieth century; contemporary art; liquid society; visual arts; holographic art.

\section{Fecha de Evaluación}

2020-05-19

\section{Fecha de Aceptación}

$2020-09-09$

\footnotetext{
- Este trabajo se ha realizado con el apoyo de la financiación recibida de un Contrato de personal posdoctoral de
} formación en docencia e investigación de la UCM, en su convocatoria de 2019. 


\section{HACIA UN UNIVERSO DE FORMAS DISUELTAS}

Espejo de una traslación desde lo apolíneo hacia lo informe, de un proceso disolutivo de antiguas certidumbres y valores, la expresión plástica, desde más de un siglo atrás, sumerge en el pozo de la conciencia aquello que hasta el momento se presentaba como verdad inmutable. Rasgos vinculados con una representación racional de la realidad darán paso a una revelación de las fuerzas ctónicas, subterráneas. Asistimos en este proceso al avance de una formatividad metamórfica, entregada a mostrar, de lo real, su naturaleza heraclítea. ${ }^{2}$ En torno a este curso se irá construyendo el imaginario por entonces venidero.

La emergencia de un mundo de formas poco dado a ser fijado, aunada justamente a la pérdida de vigencia de realidades sedimentadas, aptas para sistematizar nuestra realidad -y nuestra identidad-, ${ }^{3}$ caracterizará el espíritu de la estética, en líneas generales, privilegiada a lo largo del XX. Un torrente caótico, dinámico, enérgico, se arrastrará sin perspectiva ni deseo alguno de cristalizar, de coagular sobre el mundo objetual $-\mathrm{o}$ se valdrá de este para exponer su sustancialidad-. Nutriente de nuestras actuales construcciones teóricas y sensoriales, este curso de cuerpo fluido se abre paso hasta la contemporaneidad para derivar, tras un nuevo proceso metamórfico, en un universo de formas evanescentes, o en su caso, como si de su par dialéctico se tratase aun siempre dentro de una tendencia general de descomposición, en un atomismo desde el que cada formación trata de imponerse a la totalidad. ${ }^{4}$ Así, por tanto, las fuerzas ctónicas

\footnotetext{
${ }^{2}$ En relación con el carácter fluido de la forma expresiva en consonancia con la naturaleza del ordenamiento social del que forma parte -cuyos rasgos son evidentes, en cualquier caso y como exponemos, desde más de un siglo atrás-, alude Bauman a una "serie de procesos que estaban transformando la modernidad, llevándola de su fase 'sólida' a su fase 'líquida'. Uso aquí el término 'modernidad líquida' para la forma actual de la condición moderna, que otros autores denominan 'posmodernidad', 'modernidad tardía', 'segunda' o 'híper' modernidad. Esta modernidad se vuelve 'líquida' en el transcurso de una 'modernización' obsesiva y compulsiva que se propulsa e intensifica a sí misma, como resultado de la cual, a la manera del líquido -de ahí la elección del término-, ninguna de las etapas consecutivas de la vida social puede mantener su forma durante un tiempo prolongado. 'La disolución de todo lo sólido' ha sido la característica innata y definitoria de la forma moderna de vida desde el comienzo, pero hoy, a diferencia de ayer, las formas disueltas no han de ser reemplazadas -ni son reemplazadas- por otras solidas a las que se juzgue 'mejoradas', en el sentido de ser más sólidas y 'permanentes' que las anteriores, y en consecuencia más resistentes a la disolución. En lugar de las formas en proceso de disolución, y por lo tanto no permanentes, vienen otras que no son menos -si es que no son más- susceptibles a la disolución y por ende igualmente desprovistas de permanencia (2013, I7).

${ }^{3}$ Así, en aquellos momentos en que un ordenamiento estático e impermeable se desvanece, emerge una visión sintética y metamórfica de la realidad y de la idealidad del sujeto. Toda tendencia metamórfica es habitualmente combatida en los momentos en los que el imaginario dominante posee un grado elevado de abstracción. Un pasaje destacado de la visión del ser conforme a su naturaleza camaleónica y vinculada con la figura de Proteo, divinidad marina de naturaleza transformativa, lo recoge Pico della Mirandola en su Discurso sobre la dignidad del hombre (i496).

${ }^{4}$ Con ello nos referimos ya no solo a la licuación sino a la hipertrofiada atomización experimentada por el objeto estético y social, estado hoy comprendido como común y teorizado por nombres como Lipovetsky, el aludido Bauman o Finkielkraut. De acuerdo con el primero de ellos, según leemos en Los tiempos hipermodernos y en relación con un sistema de mercado del que participa de lleno el objeto asentado en la esfera del arte, este estado no deja de ser un apéndice camuflado del sistema: "Los elementos premodernos no se han desvanecido, sino que funcionan según una lógica moderna desregularizada y desinstitucionalizada. Incluso las clases y las culturas de clase se difuminan en beneficio del principio de la individualidad autónoma. [...] Lo que hay en circulación es una segunda modernidad, desreglamentada y globalizada,
} 
despertadas con violencia a mediados del XX (Schmitt 2007), acabarán por transmutar con este encuentro entre lo candente y lo fluido el cuerpo de nuestro imaginario en un objeto vago y vaporoso, siendo esta última la fisionomía de una realidad de tono espectral (Sloterdijk 20o6).

Regresando al punto que por el momento nos interesa, observamos en esa primera etapa de disolución objetual la necesidad de desentumecer, de derribar incluso, una estructura de pensamiento propiamente burguesa, obsesionada con mantener herméticamente cerrada su estructura superficial aun cuando sus cavidades interiores se muestran agujereadas como si de un queso se tratasen. ${ }^{5}$ En su afán por persistir, por no deshacerse de una forma sólidamente construida, advertimos el poder y a un tiempo la debilidad de lo pretendidamente objetivado-apolíneo, modelo estético ya por entonces desde tantos frentes denostado: ${ }^{6}$ su escasez de interioridad determinará su súbita descomposición, en este caso devenida de un volcánico, plutónico acontecer -de nuevo en relación con la irrupción de las, durante siglos soterradas, tensiones reprimidas o ctónicas-. Aclaramos, de pasada, que al contrario de cuanto asociamos con una interpretación heraclítea de lo real, el universo fenoménico, en los momentos en que participa de una configuración pétrea y apolínea, se muestra reacio a exponer de cada entidad su ambivalencia inherente, la cualidad metamórfica y dual de toda existencia.

Cerrando este cuadro expositivo, sintetizamos lo expuesto con la imagen de un orden formal vencido desde dos frentes. El primero de ellos remite a un impulso lentamente disolutivo, y el segundo a las telúricas energías despertadas una vez que la superficie de lo real queda definitivamente erosionada. Cabe además añadir que, así como el efecto de lo volcánico revela un súbito cambio, el de lo fluido se presenta como pausada metamorfosis delatora de transformaciones de más largo alcance. Esta traslación ya en nuestros días deja paso a un mundo objetual dominado por la disolución de las formas, por lo híbrido por tanto, y en último término, en un último giro de consecuencias desconocidas, por lo fantasmagórico, virtual y espectral, hasta el punto de que el objeto hologramático (Johnston 2015) condensa la imagen -la estructura formal- de nuestra actual cosmovisión. Cuanto tras todo ello acontece es, por el momento, un paisaje de formas aparentemente sólidas y sin embargo completamente hueras, vagas, efímeras y en cierto modo ausentes. Por todo ello entendemos que el desengaño devenido a raíz de la sustitución de categorías abstractas por realidades informes, encontrará su continuación natural en la desmesurada

sin oposición, totalmente moderna, que se basa en lo esencial en tres componentes axiomáticos de la misma modernidad: el mercado, la eficacia técnica y el individuo" (Lipovetsky y Charles, 56-57).

5 Esta necesidad del burgués de vivencia en lo delimitado-apolíneo la explora y critica Jünger en varios de sus trabajos.

${ }^{6}$ Solo cabe aquí hablar de lo apolíneo desde su comprensión parcialmente reducida, aislando el mito como si de una mónada se tratase y desligándolo de su ambivalencia fundamental. 
absorción de lo real por parte de lo espectral y virtual, esfera de realidad que pugna por acoger lo comprendido como existente, relativo hoy a todo aquello que multiplica las potencialidades del sujeto.

\section{EL PROMETEO DEVIENE EN NÁYADE}

\section{METAMORFOSIS}

A partir de este vínculo establecido entre el apagamiento apolíneo, el devenir de lo fluido y la súbita irrupción de lo ctónico, podemos tomar el Prometeo (1935) de Breker como modelo de un arte escultórico rotundo, falsa y epidérmicamente clásico, y por completo desfasado respecto de las tensiones elementales de los tiempos en que fue realizado. ${ }^{7}$ Se trata de una obra pétrea, acabada, sin margen para la confusión, tan sólidamente definida que confiere paradójicamente -y desde nuestra visión en la distancia- al mito un carácter insustancial, vacuo, incapaz de denotar algo que no sea un mero interés alegórico y hasta pedagógico: su esencia poliédrica deviene unívoca. Desde esta simplicidad formal queda escindida la naturaleza del titán dado que, con su exclusiva vinculación con una concreta idea de progreso, su imagen deja de remitir a su otra arista, aquella ceñida a la oscuridad inherente a su origen ctónico. Nada de esto último se observa en la figura de Breker, apolínea o solar solo en su superficie. Inútil resulta el engaño: de sondear bajo su piel, de indagar en las pulsiones que subyacen a su pulida forma, no queda sino constatar que reservas sustanciales avanzan y hasta preparan -como paradójicamente revela el motivo, el mito escogido por Breker-su derrumbamiento, tal y como advertimos en buena parte de los Prometeos del XX.

Efectivamente, el personaje mítico escogido -no su representación plástica convencionaldesde la distancia prefigura una violenta, inminente, erupción de fuerzas soterradas ${ }^{8}$ que encuentra su correspondiente histórico en la imagen, mítica también, de un mundo deshecho en mil pedazos. Dado que en la condición de cuanto irrumpe desde las profundidades está el repentino cambio,

\footnotetext{
7 Cuando en los años cincuenta Oteiza realice su composición homónima la despojará, muy sintomáticamente, de los atributos apolíneos que Breker le concede. La figuración, en una de sus dos versiones, de una estela con apariencia de torso, más allá de vincularse con experimentaciones técnico-compositivas, puede comprenderse como irónica visión, como irónico apagamiento de este mito remitente al alumbramiento de la civilización. La otra versión realizada por el escultor vasco, de mediados de los sesenta, puede ser atendida desde la significación de un espacio de reunión de tensiones -telúrico-solares- sobre un vaciado o circunferencia.

${ }^{8}$ Luri Medrano, en uno de sus estudios sobre Prometeo, recuerda la existencia de un Prometeo ctónico, asociado a la tierra y a lo subterráneo, también a la Diosa madre -Madre tierra-, en oposición a ese otro Prometeo, el retratado por Breker, que aludiría ante todo a su identificación exclusiva con el progreso técnico (200I, 213). El Prometeo ctónico, por su parte, es puesto por Luri Medrano en relación con los ritos órficos, "con diferentes lugares de katábasis o descenso a lo subterráneo, que al mismo tiempo que nos refuerzan la dependencia del titán con la tierra, nos descubren su relación con los cultos mistéricos e iniciáticos" (2009, I2). Finalmente, el autor realiza un vínculo entre el carácter ctónico de Prometeo y la añoranza de atemporalidad de la vida animal que el titán deja en el individuo.
} 
junto al anacronismo desde el que observamos este Prometeo en apariencia enteramente apolíneo encontramos el fondo de realidad que desenmascara su presencia como sintomática de los tiempos. El furioso fin de un ordenamiento solar -afín a lo apolíneo- es prefigurado desde el vínculo que Breker establece con lo titánico-ctónico en tanto que no es sino Prometeo, hijo de Jápeto, el personaje escogido para representar un modelo, insistimos en ello, expuesto por el escultor desde su rostro apolíneo. ${ }^{9}$ La obra -y ello ayuda a situarla e interpretarla-, resultó de un encargo de Goebbels con el objeto de ubicarla a la entrada del Ministerio de Educación y Propaganda. ${ }^{\text {ro }} \mathrm{Su}$ trabajo, como el de Riefenstahl o Speer, ha quedado en consecuencia vinculado a la propaganda estética del Reich.

En base a este punto de partida, a esta presentación de Prometeo sintomáticamente ofrecida por Breker, desde la significación y los vínculos que hemos expuesto podemos acercarnos al mito desde una distinta mirada, y así, una visión del titán desvinculada definitivamente de una estética apolínea, fijada en cambio al signo catastrófico de los tiempos, es la que va a prevalecer en el trabajo de algunos otros escultores pertenecientes a este periodo de en torno al segundo tercio del pasado siglo (Lipchitz, Zadkine, Martins, Oteiza, etc.). Si bien en las siguientes páginas seguiremos tomando como ejemplo la figura de Prometeo, lo que nos interesa por ahora es destacar no ya, como se hizo al inicio, el curso fluido que disuelve las formas a finales del XIX e inicios del XX, sino atender a un más drástico cambio. Para ello habremos de avanzar hasta la segunda mitad del XX.

Símbolo de la civilización, el fuego robado a los dioses encuentra su lugar elemental tanto en lo eidético-solar como en lo telúrico-ctónico, ${ }^{\mathrm{II}}$ aun cuando solo una vez en manos del individuo manifiesta su potencial destructivo: la visión de un titán cuyas manos son abrasadas por el fuego, según lo presenta Zadkine (1930-I940), se revela enteramente acorde con esta última significación. No encontramos, desde esta veta ofrecida por el mito, anecdótica la recurrente figuración de Prometeo en las artes tanto con anterioridad como con posterioridad a la Segunda Guerra Mundial, en tanto que su figura presagia la desgracia devenida de una hybris, ${ }^{12}$ así como invita a una renovación, a una liberación de soterrados contenidos, ${ }^{13}$ quedando de fondo el papel enteramente

\footnotetext{
9 Es, quizás, el rostro hacia abajo, junto con el pie apoyado sobre la roca, el aspecto que más podría vincular al Prometeo de Breker con su origen telúrico.

1o Cabe añadir que, al término de la guerra, el ochenta por ciento de la obra de Breker fue destruida por los aliados, si bien quedan como recuerdo numerosas fotografías.

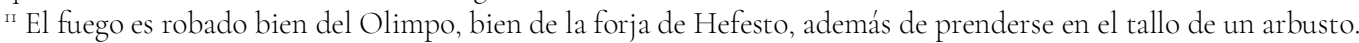

${ }^{12}$ La de la identificación del titán, pero por derivación del hombre, con la divinidad.

${ }^{13}$ Esto hemos de entenderlo a gran escala, esto es, como manifestación de una súbita irrupción de un material acumulado en el inconsciente colectivo, y desde la oposición entre lo reprimido y aquello asociado al devenir civilizador. Los elementos eminentemente racionales desde los que en apariencia se constituye dicho devenir atesoran en sus estratos los
} 
dual que relaciona al titán con los mitos de muerte simbólica y renacimiento. La interpretación de Prometeo que escultores como Brancusi (I9II), Zadkine (I930-1940), Lipchitz (1944), Maria Martins (1948) o Henry Moore (1948-1950) -que ilustrará la traducción realizada por Gide del poema homónimo de Goethe- llevan a cabo, denota tanto una victoria como un ocaso, todo ello advertido en los mencionados autores no solo desde la elección misma del motivo, claro está, sino desde una renovada forma compositiva -sea de carácter fluido, cubista o cerrada sobre sí-. En lo que aquí nos ocupa, lo interesante es observar cómo el titán se desprende de su pretendida y espuria identificación con lo exclusivamente apolíneo.

La figura de Prometeo, por recapitular, clausura una época, anuncia a su vez una próxima, nos encadena, en fin, a la historia. ${ }^{14} \mathrm{Su}$ presencia, sufriente o triunfal o ambas a un mismo tiempo, advierte de una traslación. Lejos de configurarse desde el molde apolíneo-solar privilegiado por Breker, la disolución del titán denota la metamorfosis de un claudicante imaginario, o si se prefiere la ablución de lo candente sobre unas aguas de sentido germinal. Este hecho resulta dominante en los objetos expresivos nacido de las manos de los escultores mencionados en el párrafo anterior, aun cuando hemos de comprender que la presencia recurrente de un objeto en este caso mítico ha de verse como un fenómeno simbólico -que en cualquier caso aquí nos sirve como modelo con vistas a exponer una situación común del arte occidental en el curso del periodo escogido-. Prometeo, nacido de oceánide, no solo anuncia con su pérdida de forma apolínea un agotamiento solar, un curso renovador expuesto en todos los creadores citados -excepto en Breker, claro está- desde un acontecer disolutivo, sino que abre paso, deviene él mismo, como fuerza simbólica que es -objeto metamórfico, por tanto-, en deidad -o semideidad, por ser más exactos- primordial de naturaleza fluida, y por tanto acuática. ${ }^{15}$

nutrientes de nuestro ser vinculados con lo primordial, con lo instintivo, comprendidos como nocivos desde la neurótica oposición entre razón e instinto, cultura y naturaleza.

${ }^{14}$ Cabe mencionar de modo anecdótico pero significativo que con el Prometheus situado en el complejo del centro Rockefeller, realizado por el estadounidense Paul Manship (1934), estamos ante una presentación del mito aún con tintes victoriosos que, sin embargo, visto en retrospectiva, puede ponerse en relación con los sucesos de septiembre del año $200 \mathrm{r}$. En este sentido se pronuncia el doble acento del mito: grandeza y ocaso se solapan trágicamente. El anillo que el titán se ve obligado a portar desde el momento en que es liberado por Hércules nos recuerda, de modo permanente, su vínculo con lo ctónico, su carácter cíclico asimismo.

${ }^{15}$ Comprendemos así cada objeto mítico como entidad simbólica vinculada permanentemente con un ordenamiento más amplio del que toma parte. Aquello que resaltamos con ello es la capacidad metamórfica y en permanente tensión de cada uno de los objetos que nutren un ordenamiento. Esta capacidad metamórfica y este carácter plurivalente del símbolo y del mito es algo que hallamos en toda cultura no hiperracionalizada y que, por eso mismo, se presupone en la nuestra si bien en estratos arcaicos. 


\section{DUALIDAD}

Esquiva a los artificios de la lógica, la naturaleza del mito es ante todo dual -si no poliédrica-. Podríamos decir que todo mito participa de una proyección iluminada por una determinada época, dejando en la oscuridad sus muchos otros reflejos, que pueden advertirse, en cualquier caso, actuantes de modo latente. Cuanto por ahora deseamos recalcar es la convivencia, en un mismo marco, de una expresión estética solar-sólida y de otra fluida, resultando necesario comprenderlas no como realidades opuestas sino interactuantes, tal y como el mito, al menos potencialmente, las presenta. Quebrada la piedra, piedra apolínea-solar, se derrama o surge el agua encerrada en su interior, acontecer secularmente comprendido desde su significación disolutivo-negativa. ${ }^{16}$

Como es sabido, el proceso de renovación del imaginario acontece como suceso sincrónico en lo referente a la emergencia y el decaimiento de sus unidades inherentes; así, por ejemplo, la hipertrofia racional alcanza su paroxismo al tiempo que se perfila su inminente desgracia: la horadación de un nivel superficial de la imagen mítica en su momento de mayor cohesión aparente es una constante a lo largo de la historia. En lo que toca al periodo aquí explorado, una de las expresiones más obvias y accesibles del fenómeno resulta observable en el advenimiento y auge de la psicología como irrupción del inconsciente en el plano de la conciencia. ${ }^{17}$ Este hecho, ciñéndonos a su expresión plástica, va a dejar como resultado a inicios del XX un universo de formas biomórficas, orgánicas, automotrices, vigentes aún hoy día, tal y como advertimos en la obra de Cragg, Benglis o Kapoor. Mitológicamente, y esto lo podemos rastrear desde nuestro actual interés por Warburg (2005), ${ }^{18}$ Didi-Huberman (2015 y 2017) o, en un ámbito hispanohablante, Ramón Andrés, ${ }^{19}$ la ninfa y, en general, las divinidades acuáticas, dominan nuestro imaginario. Cambia la apariencia, se distancian las constelaciones y su posición en el firmamento, no así la sustancia infinita. El mito pasa de ofrecernos un simbólico fuego a proveernos del agua con que tratar de

\footnotetext{
${ }^{16}$ Todo ello ha de llevarse a un plano metafísico que, desde una de las más evidentes lecturas, ha de vincularse con la deriva de un sistema solar-monoteísta a uno metamórfico panteísta. Cercano a ello, leemos en el Diccionario de símbolos de Cirlot: "La piedra entera simbolizó la unidad y la fuerza; la piedra rota en muchos fragmentos, el desmembramiento, la disgregación psíquica, la enfermedad, la muerte y la derrota" (368). Por nuestra parte añadimos que la disolución permite la hipotética renovación si bien desde advenedizas formas-formaciones.

${ }^{17}$ Un axioma relativo a este aspecto podría ser aquel que indica que a una mayor idealización le sobreviene una potenciación del elemento de sombra que acompaña -y para algunos autores sostiene- al primer término. Encontramos un desarrollo de esta idea en Michel Maffesoli, u obsesivamente y de modo radical en Henri Michaux (2015). Maffesoli hablará en su trabajo recogido en la bibliografía de la "l'intégration homéopatique du mal" (40), llegando a proponer, en defensa de la fusión contemporánea de lo nocturno-reprimido con lo diurno-permisible, al ángel negro como "la figure emblématique la plus expressive de la postmodernité" (24I).

${ }^{18}$ No solo desde el motivo de la ninfa y del dios melancólico, sino que la fuerte presencia de Warburg en la investigación estética desde los años 80 hemos de vincularla con un interés por los fenómenos de hibridación y pervivencia de motivos. El historiador explora la remanencia de antiguos sustratos sobre renovadas formaciones, y recíprocamente la emergencia de nuevos contenidos sobre viejos moldes.

19 Así mismo, no dejamos de destacar los trabajos de Antonio Pau sobre la presencia de la ninfa en Madrid y Barcelona (2008; 20II).
} 
apagarlo; fluida se advierte su renovada condición, y quizás nada expresa mejor esta turbadora metamorfosis que la ya aludida figura de Prometeo corriendo de una época a otra, portando ya sin conciencia de sí unas llamas abrasantes en la obra de Zadkine.

Hemos comenzado este texto aludiendo al hecho de que a finales del XIX asistíamos a una necesidad de violentar el orden apolíneo aún imperante -o prometeico desde un sentido parcial del mito, exclusivamente civilizador-. No lejano a este fenómeno, se fomentará en este mismo periodo y a modo de réplica una estética de gusto artesanal, retorno al medievo en pleno auge de la fábrica y de las posibilidades seriadas. En ello advertimos un rostro artificial e incluso sospechoso, como sospechoso tiende a parecernos toda confusión de órdenes en su estadio inicial, ${ }^{20}$ esto es, en el instante en que las demandas interiores de cada elemento se valen de una u otra argucia con tal de conseguir perpetuar sus rasgos esenciales. La alternancia y tirantez entre dominio y sumisión delata un inminente cambio de naturaleza. Los factores se invierten y este volver a un estado primordial implica una aceptación de los procesos de generación y decaimiento, un avance circular en la medida en que el ser es nuevamente comprendido desde su vínculo con lo sustancial, con sus estratos aparentemente 'superados'. ${ }^{21}$

Resulta destacable, en relación con esta idea de metamorfosis, de disolución de formas y advenimiento de renovados contenidos, que en este tránsito del XIX al XX asistimos a un nacimiento -renacimiento- y a un inminente esplendor de propuestas teológicamente neognósticas o pseudognósticas, como la teosofía y poco después la antroposofía, indicativas ambas de un estado de agrietamiento en el orden metafísico hasta el momento imperante y, en lo que a nosotros nos interesa, de alta presencia en el universo estético. ${ }^{22}$ La socavación de lo apolíneo y la prevalencia de un imaginario fluido acontecerá, en cualquier caso, de la mano de puntuales momentos eruptivos que, si por una parte evidencian el ocaso de una cosmovisión consolidada, por la otra preparan el terreno para una sostenida transformación. Así, junto a la metamorfosis pausada propia del devenir

\footnotetext{
${ }^{20}$ Esto suele ser así hasta que nuevas categorías se asientan en el imaginario de una u otra cultura, momento en que lo carente de forma a ojos del sujeto queda ya limitado -se hace, pues, controlable-.

${ }^{21}$ Encontramos a finales del XIX e inicios del XX un gusto estético por acercar inicio y ocaso, viéndose esto expresado con la constante aparición de escenas o figuras delatoras de una idea de muerte y renacimiento. Así podemos fijarnos, siendo este un lugar común, en la preponderancia que cobra en esta época la figura del Bautista (ya desde su protagonismo, ya desde el de Salomé): Rodin, Puvis de Chavannes, Beardsley, Mucha, Moreau, Wilde, Strauss, etc. El bautismo por agua, podría decirse, anuncia una nueva cosmovisión; el bautismo por fuego -realizando una equiparación desde las ideas de Teilhard de Chardin relativas al ordenamiento espiritual vinculado con su idea de noosfera (1955) - prefigura la edad del espíritu, desvelado hoy desde su semblante hologramático. En pugna con esta idea y poniendo -dialécticamente- nuestra mirada en otro orden de realidad, prevalece hoy el afán por separar pares de opuestos, la muerte de la vida primeramente, acentuándose así nuestro pánico existencial. Con ello imposibilitamos el dinamismo de nuestros recursos energéticos. Defendiéndonos de la inexistencia, en fin, desproveemos de sustancia e intensidad a la existencia.

${ }^{22}$ Lo cierto es que no podemos dejar de constatar la importancia de los presupuestos teosóficos en creadores como Mondrian, Kandinsky o Malévich, conformadores de una nueva expresión plástica.
} 
heraclíteo, asistimos a un tiempo a fenómenos remitentes, dicho grosso modo, al vulcanismo o plutonismo. ${ }^{23}$ Trasladándonos por un momento al mundo de las imágenes poéticas, y en línea con este cuadro, diremos que mientras un astro se encuentra en su cénit, el otro -trágicamente para el individuo pues cada unidad cultural se rige en ese momento por una diferente constelaciónsondea el nadir. Lo destacable aquí apunta al hecho de que, en el instante de mayor crispación, de mayor alteridad, el elemento agua y el elemento fuego actúan con igual pujanza en la configuración de nuestro imaginario, si bien cada uno compone y propicia una visión de los hechos desde un diferente lugar de la hipotética circunferencia.

La recién aludida imagen dibuja un incipiente estado expuesto por el artista contemporáneo en aquellos momentos en que, a partir de dicha dialéctica, se conforman novedosos y sintéticos modelos como los iluminados -en lo que toca a un orden simbólico y hasta mítico- en la obra de Olafur Eliasson o de Bill Viola. ${ }^{24}$ En el siguiente punto de nuestro recorrido veremos el papel del sujeto como figura que toma parte, en su situación aún cismática, de un doble pulso existencial. Veremos asimismo aquello que el arte expresa a la hora de evidenciar esta misma posición del sujeto respecto de un universo que ya no domina, un universo que se le va de las manos -como siempre se le ha ido-, a la hora de participar de una comprensión heraclítea de lo existente llamada a confundir los cauces individuales con el inmenso mar de la conciencia -computacionalmoderna.

\section{IDOLATRÍA DE LA TIERRA, ICONOCLASTIA DE LO ALADO}

La naturaleza del individuo, modelo dominante de representación escultórica a lo largo de la historia, se revela como espejo de una concreta concepción del ser, una concepción variable en función de la época y de la cultura desde la que este es contemplado. La disolución progresiva del objeto -y englobamos aquí al sujeto- característica de la primera mitad del XX, vendrá a descubrir su rostro más descarnado y violento en los trabajos desarrollados tras la Segunda Guerra Mundial

\footnotetext{
${ }^{23}$ Es preciso atender a la distinción entre plutonismo y neptunismo con cierta distancia y con atención a movimientos latentes. En este sentido, resulta destacable sin ir más lejos el hecho de que en plena erupción de la Revolución francesa, Goethe defendiese la creencia de que todo cambio acontece lenta, fluidamente. Con todo, en épocas milenaristas es común la creencia en cambios decisivos y abruptos. Más allá de este comentario orientado a no tomar los fenómenos desde una monolítica relación causa-efecto, evidentemente, el intelectual de mediados XX, golpeado por el horror bélico, abogará por un 'plutonismo' como pathos de la época, plutonismo que, con todo, en el caso de Jünger, por volver a uno de los autores ya citados, solo denota una terrible pausa antes de un renacimiento simbólico. La emergencia de este último precisa de aquellos dinamismos que Bauman asocia a lo líquido, si bien por nuestra parte consideramos, en conformidad con el pasado histórico, que a este movimiento le habrá de suceder uno próximo de cuerpo sólido.

${ }^{24}$ Es ante todo en las obras de Viola posteriores al año 2000 (Five Angels for the Millennium, The Tristan Project, The Night Journey, Bodies of Light, Martyrs), vertebradas en torno a la tensión fuego-agua, donde se expone la desconfianza hacia un sentido prometeico de la historia, así como el consecuente ejercicio de ablución y renacimiento.
} 
(en referencia a Paolozzi, Matta, Turnbull, etc.). Esta situación, en líneas generales, no será superada desde la recuperación de la figura -humana fundamentalmente-, sino que la tónica recaerá sobre el vaciado de todo objeto expresivo en un primer momento, y solo más adelante sobre la reabsorción de cualquier resto de idealismo en una cosmovisión matérica. La presente revisión fenoménica habrá de comprenderse a partir de la vinculación del ser con el aludido orden soterrado e inconsciente, objeto al que quedará ceñida asimismo el aura, ahora devenida en sombra ${ }^{25}$-al margen de poder seguir comprendiéndose como realidad meramente derivada, tal y como es entendida por Clément Rosset junto al eco y el reflejo- ${ }^{26}$ El autor francés, en efecto, emparenta estos tres motivos con todos aquellos objetos desde los que hoy es suplantada la realidad primera por una segunda de carácter, ante todo, virtual, quedando así vinculada al ya mencionado giro hacia lo espectral que define nuestro imaginario. Más adelante comentaremos algo de ello.

Volviendo a nuestro tema, los últimos coletazos de una tendencia orientada a la idealización del ser habrán de comprenderse como un acontecimiento nefasto dada la oposición radical entre dicha idealización y las demandas sustanciales del sujeto, inherentes a su propia condición biológica. ${ }^{27}$ Habrá que esperar décadas, habrá que situarse en la contemporaneidad, para que asistamos a una nueva y particular idealización apoyada, en este caso, ya no en la desatención de dicha condición natural -en su represión-, sino directamente en la alteración de los fundamentos biológicos del individuo, lo que deriva en una autodomesticación. El ocaso de la representación idealizada del ser llega hoy, en consecuencia, acompañado de una revisión absoluta de los fundamentos del 'yo'.

En lo que atañe al primer momento de esta deriva, una intelección de la naturaleza del sujeto como objeto sustancial, como entidad entregada al eterno intercambio de un proceso devorador-generador ya desde una visión puramente materialista, ${ }^{28}$ ya incluso metafísicamente reverberante ${ }^{29}$-podría hablarse de inmanencia trascendental o de términos sintéticos afines-, vendrá en adelante a conformar la representación del objeto estético barriendo a su paso los logros

\footnotetext{
${ }^{25}$ Para un estudio de la sombra en el arte moderno remitimos a Perniola (2002), Jullien (2009) y Stoichita (1999).

${ }^{26} \mathrm{El} \mathrm{eco,} \mathrm{la} \mathrm{sombra} \mathrm{y} \mathrm{el} \mathrm{reflejo} \mathrm{son} \mathrm{estudiados} \mathrm{por} \mathrm{Clément} \mathrm{Rosset} \mathrm{en} \mathrm{Impresiones} \mathrm{fugitivas} \mathrm{como} \mathrm{elementos} \mathrm{denotativos} \mathrm{de}$ una concreta realidad. Cada uno de ellos remite a un objeto que las determina. Muy distinto, para el pensador francés, es el carácter del doble, cuya función, lejos de remitir a la realidad, es disuadirnos de esta.

${ }^{27}$ A ello sigue aludiendo Maffesoli, que incide en su defensa de una des-idealización de lo real con vistas a lograr una refundamentación de lo real desde la corporalidad (2002, 5I).

${ }^{28}$ De nuevo Bauman, sin ir más lejos, en este caso en lo relativo a una comprensión neuronal del ser, expone: "La 'sociedad' se ve y se trata como una 'red', en vez de como una 'estructura' (menos aún como una 'totalidad' sólida): se percibe y se trata como una matriz de conexiones y desconexiones aleatorias y de un número esencialmente infinito de permutaciones posibles" $(2015,9)$.

${ }_{29}$ Un modelo en el arte contemporáneo expositivo de dicha fundamentación matérica del ser receptiva a lo numinoso lo encontramos en los trabajos de Anish Kapoor.
} 
y errores conquistados a lo largo de siglos y siglos de idealismo, civilización y barbarie. De acuerdo con ello, cabe mencionar que una visión sustancial del individuo en último término orientada a expresar la condición residual de todo ser -dado que el fundamento del ser se identificará con su materialidad, vinculada o no, según se acaba de indicar, con un orden trascendente-, acabará por eclipsar una serie de principios que la estética moderna no ha deseado o no ha podido recomponer, o si así lo ha hecho ha sido a costa de desproveer al sujeto de aquella identidad con la que tan cómodo se ha sentido y tanto absurdo ha generado.

Con el deseo, en suma, de suprimir un estado hipertrofiado de la individualidad, del ego y de la razón, el sujeto ha acabado por extirpar conjuntamente la concepción que de sí mismo se ha ido realizando a lo largo de los siglos. La respuesta, inmediata, todos la conocemos: la rebelión del elemento racional dilatándose al extremo o, en su caso, su aparente supresión, su deglución por la informidad de lo indistinto. Recurriendo a una más compleja pero más explícita terminología, cabría hablar de un monofisismo -por remitir a un momento asimismo de fuerte alteración o mixtura de ideaciones- invertido pre y post-milenario, un panteísmo escatológico y denso cuya nítida representación la hallamos en una divinización de lo sustancial o, de mostrarnos más concretos, en la divinización del conjunto de estratos sustentantes del ser racional-acercándonos desde aquí a Lacan (1999)-. Divinización, pues, del sujeto a partir de su ser animal, ${ }^{30}$ divinización ampliable hoy día a todo cuanto del ser se comprende como su realidad fundamental, aspecto vinculado a una atomización del individuo e incluso, como veremos, a su definitivo vaciamiento: la razón no ya como corolario y culmen de nuestra identidad, como su parte salvable también, sino como súbdita de la materia sintiente.

En paralelo, asistimos a un fenómeno de hibridismo tanto humano-animal, humanovegetal, como humano-computacional (Carpio s/p), dándose así carta blanca a una renovada proyección de las realidades que concretan la actual cosmovisión. Conforme a esta, la idealización o divinización del sujeto no coincide ya con un orden convencionalmente metafísico sino con uno

\footnotetext{
$3^{\circ}$ Crítico al respecto, señala Agamben en relación con la dualidad hombre-animal: "Cuando la diferencia se anula y los dos términos entran en una relación de vaciamiento recíproco -como parece suceder hoy- también desaparece la diferencia entre el ser y la nada, lo lícito y lo ilícito, lo divino y lo demoníaco, y, en su lugar, aparece algo para lo que ni siquiera parecemos disponer de nombres" (36). Tres cuartos de siglo atrás, Kojève, con preclara visión, hacía referencia a esta condición animal si bien sin conato alguno de vincularlo con una base espiritual. La cita, tomada de su Introduction à la lecture de Hegel, Gallimard, Paris, 1979, 436 (Iae edición, 1947), la encontramos en el recién citado texto de Agamben: "Si el Hombre re-deviene un animal, sus artes, sus amores y sus juegos deberán re-devenir también, puramente 'naturales'. Así pues, habría que admitir que después del fin de la Historia, los hombres construirán sus edificios y sus obras de arte como los pájaros construyen sus nidos y las arañas tejen sus telas, que ejecutarán conciertos musicales de la misma forma que las ranas y las cigarras, que jugarán como juegan los animales jóvenes y se entregarán a su amor igual que lo hacen los animales adultos. Pero no se puede decir, entonces, que todo eso 'hace feliz al Hombre'. Habría que decir que los animales post-históricos de la especie Homo sapiens (que vivirán en la abundancia y en plena seguridad) estarán contentos en función de su comportamiento artístico, erótico y lúdico, visto que, por definición, se contentarán con él” (19-20).
} 
material, lo que en último término lleva a una sui generis divinización por medios tecnológicos Antonio Diéguez hablará, cercano a ello, de una "resurrección computacional" (56)-. Desde este último terreno pasamos, en cualquier caso, a representar un renovado idealismo -si así se lo quiere denominar- cuya hipotética realización requiere del dominio y la modificación de nuestro patrón biológico/genético. Cuanto se va a representar y en cierto modo se idolatrará en la cosmovisión imperante, será la naturaleza elemental de toda realidad -no solo del sujeto-, esto es, aquello reivindicado desde su deificable sustancialidad. Se idolatra, pues, el barro, y se desestima lo restante, el espíritu o la nada. La obra, como el sujeto, se cierra sobre sí: la tierra, por sí misma, se ve en consecuencia animada -o dicho con más propiedad, meramente dinamizada-. Monofisismo invertido, según dijimos, en la medida en que el sujeto se reverencia a sí mismo desde su confianza en trascenderse a partir de su novedoso orden eidético, ceñido a las posibilidades genéticas y computacionales; desde estos márgenes el ser ilumina su nuevo tejido trascendente: idolatría de la tierra-autodivinización incluso del propio sujeto a modo de atomizado neognosticismo, como ya adelantamos-, iconoclastia de lo alado.

\section{HIBRIDISMO Y ATOMIZACIÓN}

Llegados a los márgenes de la estética contemporánea, sumergidos de lleno en su ser-sustancial, habremos de atravesar una galería de esfinges y monstruos, pasillos de un hipotético museo a medio camino entre el de arte y el de ciencias naturales. Lejos de representar la figura del sujeto, el creador prefigura nuestra inminente condición, o disuelve la actual para mostrarnos su esencia. Si tomamos como ejemplo la obra del artista plástico y audiovisual Pierre Huyghe (París, 1962), en concreto su reciente trabajo (Untitled) Human Mask (2014), no podremos sino reconocernos en la figura que, con gestos y movimientos simiescos, recorre desquiciada de un lugar a otro las habitaciones en las que permanece recluida. Este simio, portador de una máscara con apariencia humana aun con rasgos no definidos, no individualizados, remitentes a la condición esencial de todo individuo, nos pone frente a frente con nuestra propia naturaleza: mono civilizado, mono bárbaro, mono domesticado. Lejos de contemplarse en relación con un sublimado orden, el ser retrotrae su mirada hacia su animalidad. En la aludida obra de Huyghe la persona es representada como simio, y el mundo, claustrofóbico, como una serie de descuidadas habitaciones. Desde nuestro ser animal, la cultura, la historia, el uso del lenguaje, se desenmascaran como meros recubrimientos, como niveles superpuestos de falacia, mecanismos de embuste y desencuentro, residuos civilizatorios, en suma. La obra -al margen de los valores formales- guarda lazos con 2001, aun cuando en el trabajo de Huyghe todo se presenta desde una áspera y desoladora desnudez. 
La tendencia hacia la acentuación de la condición animal va a adoptar innumerables rostros en la estética reciente, proponiendo inagotables propuestas exitosas ya desde finales del pasado siglo no solo en el marco delimitado por el art performance, sino por supuesto en cada una de las artes. En línea con la trayectoria y las demandas de este curso, trabajos como los de Liu Xue o Kate Clark desde las artes plásticas, Joachim Luetke desde el multimedia en una exploración a menudo orientada a la definición de estéticas ajenas (Marilyn Manson o bandas black metal fundamentalmente escandinavas), Matthew Barney asimismo desde el audiovisual, y un largo etcétera, revisten el imaginario con una amplia gama de formas híbridas, algunas de ellas situadas en las proximidades o directamente dentro de los límites de una estética posthumanista, lo que no puede dejar de interesarnos. Llegados a este lugar, eludiendo una mera enumeración de tendencias, nos replegamos sobre un molde abstracto y destacamos de esta deriva un motivo esencial y común a cada una de ellas como es el de la negación de una identidad construida sobre la racionalidad y comprendida desde un excluyente aislamiento, en consonancia así, resulta interesante añadir, con momentos culturales en los que las relaciones de transferencia entre el sujeto y su entorno permanecían activas. Este estadio psíquico se refleja y determina los orígenes del arte, siendo habitual hallar en la pintura parietal al individuo definido a partir de su constitución como sujeto y objeto a un tiempo. La imbricación del ser con su realidad externa, su coexistencia anímica con fuerzas y potencialidades animales, vegetales u objetuales, ha de comprenderse desde motivos ya bosquejados como, ante todo, la constitución del yo no desde su mera racionalidad, sino desde su permeabilidad elemental hacia cuanto de un modo u otro lo complementa, sin olvidar aquí, claro está, el material psíquico explorado por Michaux y tenido en momentos de neurosis como doble de uno mismo. Esta estructura identitaria de naturaleza porosa, sin embargo, quedará secularmente desterrada a dominios tenidos por abominables, escisión posibilitada en el momento en el que el sujeto se impone como criatura teológicamente elegida, esto es, con la revolucionaria irrupción de los credos monoteístas. Pudiera decirse que la antropomórfica y antropológica naturaleza del dios se revelará entonces especularmente excluyente, privando al ser de aquello que más adelante será tenido por denostado fondo telúrico. ${ }^{31}$ Se trata este de un modelo identitario que participa hoy de un nuevo giro si bien desde la desarticulación del concepto de sujeto. En este último periodo, el actual, es preciso hablar, por tanto, si no ya de una desanimación de lo real, al menos sí de una reanimación de lo real por medios inanimados.

\footnotetext{
${ }^{31}$ De esta misma oposición participan los estratos mitológicos -y aquí encontramos el relato prometeico- exponentes de la tensión entre los dioses solares y las divinidades telúricas o instintuales.
} 
La deriva recién mencionada es óptimamente rastreable y se articula al compás de las sucesivas cosmovisiones. Cuanto aquí estrictamente nos ocupa, por no alejarnos de nuestro epicentro, es la natural tendencia del individuo a ampliar los límites de la personalidad por medio de modelos de transferencia. Desde este milenario propósito -la multiplicación de las potencialidades del sujeto por hibridismo o combinación- podemos seguir iluminando la deriva estética con el afán de advertir lo que cabría comprender, trazando un milenario arco, como una traslación del hombre-animal prehistórico al hombre genéticamente modificado, saltando así de lo mágico-simbólico a lo mecanizado-causal. Conforme a este germen de hibridación, a partir de modelos epidérmicos pero orientados sin duda a motivar una reflexión sobre el aludido fenómeno, cabe destacar la obra de Sterlac, Orlan, Kac o Kira O'Reilly (Miah, 20I2), como propuestas desde las que cabe vincular epigonales modalidades expresivas a urgentes modelos de hibridación, tal y como se explicita en el siguiente comentario de Vilodre Goellner y Souza Couto:

Sterlac, Orlan y Gunther von Hagens tienen mucho en común: son artistas-cientificistas, forman parte de una generación que vive cotidianamente las más diversas tecnologías proteicas y de comunicación y experimentan en el cuerpo los efectos de la relación íntima entre hombres y máquinas. Los tres promueven mezclas entre lo orgánico y lo sintético, lo natural y lo superficial, exploran los límites físicos e intentan traspasarlos ampliando la capacidad y la potencia corporal por medio de las tecnologías. De ese modo dan visibilidad a una estética proteica, cirugía y plástica de los cuerpos en estos tiempos de cibercultura (2007, II7).

Lo cierto es que nada de lo recién expuesto puede resultarnos ajeno pues, al margen de continuar -aun desde otros cauces- con la búsqueda planteada desde los inicios estéticos, la indagación de nuevas posibilidades orgánicas queda asociada a potencialidades tecnológicas que afectan hoy a distintas esferas existenciales, realidad que progresivamente deriva en una redefinición del concepto de ser. Cuanto a un tiempo se articula es una nueva concepción de lo divino -ontología mecanicista- de cuerpo y psique especular al nuestro propio. No nos extrañará en este sentido el que a la larga cadena de hibridación -simbólica y mecánica- definida por la historia -en sentido laxo-, se adhiera un apéndice genético y neuronal que viene a evidenciar el sustrato asimilado por el sujeto: ni animal ni humano: enteramente divino, una vez más en relación especular con su concepción de este último término.

Según observamos, la potencialización de los atributos del sujeto no se busca en este caso por medio de asociaciones simbólicas, sino por hibridaciones mecánicas, orgánicas, neurológicas y computacionales, siendo en este sentido la medicina, la informática, la ingeniería, algunas de las disciplinas desde las que el sujeto reabsorbe hoy su perdida animalidad al tiempo que se redefine a sí mismo. Así expuesto, la recuperación de la animalidad por parte del científico y del artista contemporáneo -sintetizados ambos en la figura del informático, del sujeto técnico- cristaliza sin 
embargo en un alejamiento de los fundamentos sobre los que el ser previamente se sustentaba. De este modo, frente a la utópica vivencia en lo instintivo y anómico -quien así participa de la existencia es de inmediato un individuo señalado y sospechoso en tanto que ineficiente-, el sujeto se va aproximando a una condición menos individualizada y fundamentada, por el contrario, sobre un esquema reticular.

Lejos de encarnar un hibridismo metafórico, aun siendo variados los cauces seguidos por esta redefinición, aquello que secularmente cristalizó por medio de rituales de transferencia hoy se reactiva por vía científica, tal y como advertimos con la implantación de órganos o, en general, de tejidos animales, así como con cualquier proyecto de modificación genética. Conforme a este hibridismo asumido no solo simbólica sino fácticamente, asistimos por tanto a lo que parece un nuevo salto en el proceso de autodomesticación,$^{32} \mathrm{o}$ en este caso mecanización del individuo. En este forzar la cerradura clásica del ser, la estética, en alianza con la técnica, se afianza en su papel moldeador de la realidad tanto externa como interna, último escalón de un omnívoro proceso. La presente deriva de la naturaleza humana, añadimos aún, encuentra su correspondiente en las disciplinas que culturalmente regulan la realidad del ser -política, derecho, etc.-, objetos asimismo conceptualmente fragmentados dada su permanentemente renovada condición, cambiante hasta el solapamiento constante de límites. A partir de esta visión de un sujeto que sustituye lo biológico por lo mecánico y de este modo vincula ambos conceptos, una vez sumidos en una dinámica reduccionista, la deriva expuesta por Agamben (2010, 36) se cumple punto por punto para acabar por identificar la esencia del ser con cualquier entidad analizable. De acuerdo con lo señalado líneas atrás y con cuanto nos interesa en este tramo final del trabajo, el sujeto no solo se descubre o se contempla hoy desde su ser instintivo, sino que comienza a comprenderse y definirse desde su ser atomizado, ya sea neuronal, genético o, en general, computacional (Carpio s/p). El repliegue sobre nuestra animalidad sustentante encuentra sorprendentes y peligrosos cauces desde los que nuestra herida condición se obceca en recomponerse.

Antes de cerrar este epígrafe acudiremos a un último modelo expresivo con el objeto de observar cómo una de las derivas fundamentales de este curso, aquella que define al sujeto desde su ser reticular, es presentada por Pierre Huyghe, quien aborda este fenómeno -comprensible desde la formación de una psique colectiva por vía no simbólica sino neuronal- desde un planteamiento original y efectivo. De aproximarnos a su reciente trabajo Untilled (Liegender Frauenakt), de 2oII-

\footnotetext{
${ }^{32}$ Cabe reflexionar si lo que comprendemos como autodomesticación no es sino un nuevo concepto antropocéntrico desde el que nos creemos dominar lo que, como se propone desde un sector del pensamiento, en verdad nos domina. En tal caso el sujeto se presenta como herramienta, como medio, de una potencia mayor que nos conforma y nos cosifica -nos mecaniza-.
} 
2012, contemplaremos lo que podría identificarse como novedosa situación del ser en su incipiente imaginario. La esfinge que forma parte de la instalación -esfinge de cuerpo más sofisticado que el heredado del periodo grecolatino, y en ello no deja de advertirse un gesto irónico- incorpora un panal de abejas a modo de rostro. Cuanto de ello aquí nos interesa concierne a la identificación entre la cabeza -red neuronal-y el enjambre de abejas -modelo organizativo-, corporeizándose así una metáfora altamente significativa remitente a la traslación de una inteligencia -e incluso de una percepción del yo- individualizada hacia una inteligencia, en este caso -como nueva posibilidad del sujeto- reticular, colectiva -con el consiguiente cambio de autopercepción experimentado por parte del individuo, que deja a la postre de ser tal-.

No ahondaremos en ello y nos abrimos ya paso hacia el siguiente estadio de este curso secular. A lo largo de este punto hemos deseado exponer un paradigma llamado a solapar unos órdenes con otros, todos ellos denotativos del modo en que el individuo comienza a observarse y a entenderse a sí mismo. ${ }^{33}$ La persona, podemos sintetizar, se revela como esfinge varada en ninguna parte pues su esencia es un todo y a un tiempo una nada. Como resultado de todo ello, detrás de este sincretismo se advierte un sorprendente aspecto: siendo el 'yo' objeto de idolatría para el individuo contemporáneo, su idealización absoluta -aquella desde la que, en un gesto de hybris y a modo de aporía, se autoproclama cocreador de la creación- y su ser elemental -lo que en último término hoy remite a su comprensión de sí desde su atomización- acaban por identificarse. En este desprendimiento de idealidad y aura aquello que de fondo se vislumbra apunta, se quiera o no, a una nueva idealidad dado que se vincula al sujeto, se lo representa, desde aquellos aspectos que lo ponen, una vez más, en relación con objetos con los que dota de forma su afán de inmortalidad. Si ayer esta vía de acceso a lo trascendente quedaba aunada a un orden metafísico y externo, ${ }^{34}$ hoy es demandada en un inmanente horizonte computacional y genético -desde la superación de nuestros patrones naturales-, en un vaciado de lo individual sobre un tejido artificial, dado que, en este sentido, todo por ahora se presenta como una apertura de puertas y más puertas sin que alcancemos a ver qué es lo que nos depara este fáustico afán de dinámica irrefrenable.

\footnotetext{
${ }_{33}$ Resulta preciso indicar, a modo meramente de inciso, que el ser integra en su concepción de sí, de modo constante, cada aspecto de realidad que vincula con su identidad -sea concreta o abstracta-. Esto deviene en un carácter, en una visión propia, permanente y consustancialmente híbrida, visión que se hace explícita en momentos de ruptura con sólidos paradigmas.

${ }^{34}$ Tal y como queda representado por la identidad de proporciones y semejanza entre el ser humano y la divinidad en la escultura de la Antigüedad clásica y en otras tantas tradiciones.
} 


\section{BREVE INCURSIÓN POR LA REALIDAD HOLOGRAMÁTICA}

Cerraremos nuestro recorrido exponiendo sucintamente aquello que ha de comprenderse como nuevo espacio de ser e idealidad -ahora unificados-, un mundo de posibilidades impredecibles y de significación fundamental en la configuración de la estética reciente. Como último molde de las idealizaciones expresadas por el creador plástico -entendiendo este término en sentido amplio, esto es, tomando como plásticas las modelaciones del espacio por medio de luces y, en general, de material audiovisual-, hemos de mencionar las posibilidades virtuales y hologramáticas exploradas desde su conformación a modo de nuevos tejidos desde los que se moldea nuestra identidad y nuestra realidad. ${ }^{35}$ Nos basta con señalar este fenómeno y remitimos, por lo demás, a la bibliografía para quien desee explorar con detalle aspectos sobre la materia -véase Wilber (1982), Johnston (2009 y 2015) y Respini (2018)-. En lo que respecta a la expresión estética de este objeto, si bien sería posible ejemplificar con algún otro trabajo de Huyghe como One Million Kingdoms (200I), resulta más apropiado, de nuevo para quien se muestre interesado, sondear la obra de Cao Fei o de Antoine Catala -reseñados ambos en el catálogo de exposición Art in the Age of the Internet, 1989 to Today, igualmente citado en la bibliografía-, así como la de algunos pioneros como Selwyn Lissack -quien trabajó junto a Dalí en la creación hologramática en la década de los setenta- ${ }^{36}$ Bruce Nauman o Margaret Benyon. ${ }^{37}$

Más allá de estos nombres, a la hora de engarzar el imaginario actual con el modelo simbólico del que hemos partido en estas páginas, nos interesa incidir en el hecho de que el rostro de nuestro imaginario, lejos de acentuar una forma pétrea, solar y estática, atraviesa insospechables fronteras para acabar hoy por coagular, vaporosa y fugitivamente, sobre espectrales realidades, sobre universos virtuales cuyas potencialidades apenas somos capaces de advertir. Esta situación liminal, que inevitablemente nos sitúa en el terreno de lo ambiguo, propone una objetualidad llamada a sustituir una intelección continua y sin saltos de lo real, por otra definitoria del momento presente, ceñida a un nervioso apagado y encendido de redes, a la posición tomada,

\footnotetext{
35 Regresando a un punto que dejamos atrás relativo a la energetización o espiritualización de la materia, las ideas de Teilhard de Chardin, en concreto su comprensión de la noosfera -término tomado por De Chardin de Vladímir Vernadski-, lejos de quedar obsoletas, son recuperadas hoy desde diversos frentes y puestas en relación con el mundo hologramático, virtual. Valga al respecto la referencia a la obra editada por Ken Wilber The Holographic Paradigm and Other Paradoxes (1982), y ante todo su Sex, Ecology, Spirituality (1995), en la que vierte dicho término sobre la realidad actual desde presupuestos psicológicos de carácter holístico.

${ }^{36}$ Remitimos a la consulta del catálogo de la exposición realizada en 2012 en el Castillo Gala Dali de Púbol con el título: "3DALI. Dalí y la holografía: realidad virtual e ilusión de realidad", cuyas referencias incluimos en la bibliografía.

${ }_{37}$ Este interés por lo hologramático en las artes lo recoge Johnston en su mencionado trabajo: "Holography exemplifies an intellectual concept that greatly generalized concepts of optics and imaging, and of a technology that, for a quarter century, excited considerable enthusiasm from corporate researchers, university scientists, artisans, and artists" (2009, II2).
} 
asimismo, por un metafórico interruptor. De todo este tejido fabulosamente artificial, apoyándonos de nuevo en el mundo de las imágenes plásticas, acaso es el holograma el objeto estético que más certeramente formaliza esta liminal condición:

The hologram creates a presence but no substance, except as light and meaning. This object/image ambiguity is fundamental in holography because it creates a tension between real and virtual far more obvious than with any other medium; it is found in many holographic artworks. On the other hand, within your containers and boxes, the illusory images are associated with the real object. Material object + light object. So all objects become ambiguous. (Harman, 2020, 6) $)^{38}$

El presente lugar fronterizo, que no solo constituye y define la corporeidad/energética de la obra, sino que explora a un tiempo, en línea con los artistas-científicos señalados más arriba, la naturaleza de nuestra realidad, de nuestro entendimiento de ella al menos, se propone como ámbito priorizado por el artista contemporáneo. Sobre el holograma cabría escribir toda una fenomenología articulada desde la concepción de lo espacial, según van haciendo -en añadidura al trabajo de los mencionados pioneros- con su obra nombres como James Turrell, Michael Snow, la citada Mary Harman o August Muth, por nombrar algunos de los que focalizan el monográfico "Holography-A Critical Debate within Contemporary Visual Culture", recientemente editado en la revista Arts, de donde hemos tomado el texto arriba recogido. Con afán de sintetizar lo en él expuesto, diremos que el interés en las posibilidades ofrecidas tanto por una comprensión ambivalente de la luz, como por una introspección de la naturaleza del cuerpo y del espacio, evidencia un deseo de resaltar una identidad entre el objeto y el sujeto conforme a los presupuestos de nuestro imaginario. Dejemos asimismo que sea uno de estos autores quien lo exprese con sus palabras:

Holograms are truly extraordinary. They exist as an intermediary between our terrestrial existence and the mysteries of light. My holographic artworks transform light with its non-material carácter into multi-dimensional and tactile creations of material light. In these works I use light as a material, sculpting photons into a luminous essence of polychromatic color and mystery. They exhibit a material yet ethereal nature that invites examination and exploration. (Muth, 2020, 6-7)

Escapando las posibilidades de esta fenomenología hologramática a las pretensiones y posibilidades de nuestro trabajo, lo nuclear y decisivo, conviene insistir volviendo al hilo que ha ido vertebrando estas páginas, reside en la renovada forma que va adquiriendo el espectro simbólico actual en tanto que el elemento que prima remite a una desmaterialización fenoménica, o a una redefinición de lo fenoménico, esto es, a una renovada física y metafísica. Desde este punto podría aún hacerse referencia a un nuevo aspecto en el que no ahondaremos si bien lo señalaremos, nos

\footnotetext{
${ }^{38}$ Palabras de Jacques Desbiens a Mary Harman, creadores ambos de formas por medio de este ambiguo material a caballo entre lo existente e inexistente. Ambos autores dejan su testimonio sobre el sentido del holograma en el monográfico de la revista Arts recogido en la bibliografía.
} 
referimos en concreto a la emergencia de modelos expresivos insertados en la esfera de la cultura de masas, modelos desde los que una realidad fantasmagórica, galvanizada, suplanta exitosamente a aquella otra orgánica -al menos desde una concepción clásica del término-. Remitimos sin más al éxito de Hatsune Miku, estrella pop de naturaleza incorpórea, o a los más inquietantes conciertos protagonizados por espectros, en tanto que los protagonistas de estos espectáculos son hologramas que cobran la forma de Maria Callas, Dio o Michael Jackson, entre algunos otros.

Reformulando las ideas expuestas en este último epígrafe, advertimos que el afán de simbolizar, lejos de difuminarse, se comprende en nuestra época acorde con las nuevas necesidades e idealizaciones del individuo. Nuevas idealizaciones, a fin de cuentas, requieren de nuevos conceptos de aura, o en su caso de nuevas formas desde las que se posibiliten asimismo novedosos sentidos. El artista, entre tanto, se obceca y empeña en descubrir, en formular y materializar, él también, estas nuevas imágenes de nuestro tiempo, aun cuando por ahora solo encuentra fantasmas.

\section{CONCLUSIÓN}

El gusto por un arte entregado a la combinación de formas, al despertar de imágenes metamórficas e incluso tendente a la superposición de diferentes órdenes, se acentúa en aquellos periodos llamados a desvelar un cambio de cosmovisión aún sin cristalizar. Es el signo de lo transitorio, de lo cambiante, y lo encontramos en todo estrato cultural, tanto en la prehistoria ${ }^{39}$ como en el medievo tardío, ${ }^{40}$ tanto en el barroco ${ }^{41}$ como en la contemporaneidad. ${ }^{42}$ En esta última, como observamos en la aludida obra de Kubrick, los extremos se tocan, si es que alguna vez han estado alejados. Desde este mismo lugar advertimos la convivencia de rasgos humanos con rasgos animales e incluso vegetales, la convivencia asimismo de estos últimos con aquellos otros vinculados con una comprensión de lo real atomizada o incluso vaciada de sustancia. Nada hay de nuevo: en el seno de culturas y religiones más permeables, más plásticas que la global-occidental-caso de la hindú tradicional o de la azteca-, resulta común mostrar simbólicamente al sujeto desde su identificación con apariencias del mundo vegetal, animal, divino u objetual. En estos casos el yo, la

\footnotetext{
39 A modo de ejemplo, remitimos a las figuras híbridas del Paleolítico superior, indicativas de una identificación entre la persona y concretos aspectos animales (vid. Leroi-Gourhan 1987, I06-107).

${ }^{40}$ En relación con la significación del hibridismo a lo largo del medievo, véase Le Goff (2003, 164).

4r "Para el barroco, el monstruo es una alegoría de la inestabilidad de las categorías, es un espejo deformado de las categorías estables de lo humano definidas desde la estética clásica. El monstruo es una distopía, una distorsión en sí mismo, un atentado a la forma, una revelación de su precariedad, una evidencia del carácter alucinatorio de lo especular, la extrañeza que sugiere la condición de exiliado del hombre. [...] Dicha experiencia de exilio tiene que ver con la mutación cosmológica de los siglos XVI y XVII. [...] En un universo en mutación, es lógico que el hombre vea en el monstruo la mutación de su propia identidad, la pérdida de la centralidad que le daba ser la imagen y semejanza de Dios" (Martínez Arias, 48-49).

${ }^{42}$ En este caso numerosos ejemplos son presentados por Jean Clair en su trabajo Hubris (2012).
} 
individualidad, queda en entredicho sin que suponga el decaimiento que ello supone a ojos de la conciencia históricamente privilegiada en occidente. Lo que en esta se identifica con una reducción de la persona, en culturas menos sobrecargadas de tejidos conceptuales alrededor de ese yo implica su ensanchamiento. Lo definitorio del sujeto, en estos casos, es cuanto rebosa de él, y en modo alguno aquello que queda asimilado a sus atributos más o menos permanentes, más o menos explícitos, esto es, a su esclerotizada conciencia.

La persona, en todo este panorama y en lo relativo a nuestro marco cultural, se ve desposeída de aquellas categorías que a lo largo de siglos han sintetizado sus cualidades, perdiéndose ahora en envolturas o crisálidas venidas a desvelar un aspecto de su naturaleza apenas explorado. Lo destacable aquí concierne a cómo el sujeto se advierte a sí mismo, a la parte de sí que conoce y que comprende o cree comprender pues, según el modo en que el sujeto se percibe, configura sus particulares e incesantes idealizaciones. En el ahondamiento de su escurridiza naturaleza -recordemos de nuevo a Pico- el ser humano repara exacta y precisamente en aquello que también es: entidad vegetal y animal, un objeto, una máquina o un dios; se ve mortal e inmortal, diabólico y seráfico, y en esta búsqueda de pruebas encuentra todos los rastros de sí excepto uno propio, excepto un algo definitorio, advirtiéndose siempre como un otro lejano y hasta extraño en su afán de iluminarse.

\section{REFERENCIAS}

Agamben, Giorgio. Lo abierto. El hombre y el animal. Valencia: Pre-textos, 2010.

Aguer, Montse, Alice Cooper, Salvador Dalí y Selwyn Lyssack. 3DALÍ. Dalí y la holografía: realidad virtual e ilusión de la realidad. Figueres: DAS Edicions, 2012.

Andrés, Ramón. Claudio Monteverdi. 'Lamento della Ninfa'. Barcelona: Acantilado, 20r7.

Bauman, Zygmunt. La cultura en el mundo de la modernidad líquida. Madrid: Fondo de Cultura Económica, 2013.

Bauman, Zygmunt. Tiempos líquidos. Vivir en una época de incertidumbre. Barcelona: Tusquets, 2015.

Carpio, Mario. "Olvidemos lo 'Post-Digital': La innovación en la arquitectura apenas comienza". Plataforma arquitectura, 20I8, s/p.

Clair, Jean. Hubris. La fabrique du monstre dans l'art moderne. Homoncules, Géants et Acéphales. Paris: Gallimard, 2012.

Chardin, Pierre Teilhard de. Le phénomène humain. Paris: Seuil, 1955. 
Cirlot, Juan Eduardo. Diccionario de símbolos. Madrid: Siruela, 2007.

Della Mirandola, Giovanni Pico. Discurso sobre la dignidad del hombre. México D.F.: Universidad Nacional Autónoma de México, 2003.

Diéguez, Antonio. Transhumanismo. La búsqueda tecnológica del mejoramiento humano. Barcelona: Herder, 20I8.

Didi-Huberman, Georges. Ninfa fluida. Essai sur le drapé-désir. Paris: Gallimard, 2015.

Didi-Huberman, Georges. Ninfa profunda. Essai sur le drapé-tourmente. Paris: Editions Gallimard, 2017.

Harman, Mary. "Holographic Reconstruction of Objects in a Mixed-Reality, Post-Truth Era: A Personal Essay". Arts, 8.3, 2019: I-9.

Johnston, Sean F. "Representing Holographyin Museum Collections". Illuminating Instruments. Eds. Peter Morris y Klaus Staubermann. Washington DC: Smithsonian University Press, 2009. 97-II6.

Johnston, Sean F. Holograms. A Cultural History. Oxford: Oxford University Press, 2015.

Jullien, François. La sombra en el cuadro. Del mal o de lo negativo. Madrid: Arena, 20o9.

Jünger, Ernst. El trabajador. Dominio y figura. Barcelona: Tusquets, I990.

Lacan, Jacques. El seminario Lacan, II. Los cuatro conceptos fundamentales del psicoanálisis. Buenos Aires: Paidós, 1999.

Le Goff, Jacques y Nicolas Truong. Une histoire du corps au Moyen Âge. France: Liana Levi, 2003.

Leroi-Gourhan, André. Las religiones de la prehistoria. Barcelona: Lerna, 1987.

Lipovetsky, Gilles y Sébastien Charles. Los tiempos hipermodernos. Barcelona: Anagrama, $20{ }^{2}$.

Luri Medrano, Gregorio. "El Prometeo ctónico". Ex novo. Revista d'Història i Humanitats 5, 2009: 7-20.

Luri Medrano, Gregorio. Biografías de un mito. Prometeos. Madrid: Trotta, zoor.

Maffesoli, Michel. La part du diable. Précis de subversión postmoderne. France: Flammarion, 2002.

Martínez Arias, Víctor Leonardo. "De lo demoníaco a lo abyecto. Figuras de lo terrible en el arte moderno". Tesis doctoral. Universitat Pompeu Fabra, 2015.

Miah, Andy. "Bioarte: actuación transhumana y posthumana". Teknokultura. Revista de Cultura Digital y Movimientos Sociales 9.I, 20I2: 85-IO4.

Michaux, Henri. Una vía para la insubordinación. Barcelona: Alpha Decay, 2015.

Muth, August. "Material Light-In the Realm of the Photon". Arts 9.4, 2020: I-8.

Pau, Antonio. Las ninfas de Madrid. Madrid: Trotta, 2008. 
Pau, Antonio. Las ninfas de Barcelona. Madrid: Trotta, 20Ir.

Perniola, Mario. El arte y su sombra. Madrid: Cátedra, 2002.

Respini, Eva, ed. Art in the Age of the Internet, 1989 to Today. USA: Yale University Press, 2018.

Rosset, Clémént. Impressions fugitives: l'ombre, le reflet, l'echo. Paris: Minuit, 2004.

Schmitt, Carl. Tierra y mar, Una reflexión sobre la historia universal. Madrid: Trotta, 2007.

Sloterdijk, Peter. Esferas III. Espumas. Madrid: Siruela, 2006.

Stoichita, Victor I. Breve historia de la sombra. Madrid: Siruela, 1999.

Vernadsky, Vladimir I. La biosfera. Madrid: Antonio Machado, I997.

Vilodre Goellner, Silvana y Edvaldo Souza Couto. "La estética de los cuerpos mutantes en las obras de Sterlac, Orlan y Gunter von Hagens". Opción 23.54, 2007: II4-I3r.

Warburg, Aby. El renacimiento del paganismo: aportaciones a la historia cultural del Renacimiento europeo. Madrid: Alianza, 2005.

Wilber, Ken, ed. The Holographic Paradigm and Other Paradoxes: Exploring the Leading Edge of Science. USA: Shambhala, 1982.

Wilber, Ken. Ecology, Spirituality: The Spirit of Evolution. USA: Shambhala, I995. 